\title{
Damage tolerant evaluation of cracked stiffened panels under fatigue loading
}

\author{
A RAMA CHANDRA MURTHY, G S PALANI* \\ and NAGESH R IYER
}

CSIR-Structural Engineering Research Centre, CSIR Campus, Taramani, Chennai 600 113, India

e-mail: pal@serc.res.in

\begin{abstract}
This paper presents the methodologies for damage tolerant evaluation of stiffened panels under fatigue loading. The two major objectives of damage tolerant evaluation, namely, the remaining life prediction and residual strength evaluation of stiffened panels have been discussed. Concentric and eccentric stiffeners have been considered. Stress intensity factor for a stiffened panel has been computed by using parametric equations of numerically integrated modified virtual crack closure integral technique. Various methodologies for residual strength evaluation, namely, plastic collapse condition, fracture toughness criterion and remaining life approach have been described. Effect of various stiffener sizes and stiffener type (concentric and eccentric stiffeners) on remaining life and residual strength has been studied under constant amplitude load. From the studies, it has been observed that the predicted life is significantly higher with concentric and eccentric stiffener cases compared to the respective unstiffened cases. The percentage increase in life is relatively more in the case of concentric stiffener compared to that of eccentric stiffener case for the same stiffener size and moment of inertia. From the studies, it has also been observed that the predicted residual strength using remaining life approach is lower compared to other methods, namely, plastic collapse condition and fracture toughness criterion and hence remaining life approach will govern the design. It is noted that residual strength increases with the increase of stiffener size.
\end{abstract}

Keywords. Stiffened panels; stress intensity factor; fatigue and fracture; damage tolerant evaluation; remaining life; residual strength.

\section{Introduction}

Most of the structures such as nuclear containments, reactor vessels, flyovers, high-rise buildings, aerospace structures, ship hulls, bridges and offshore structures are required to operate under controllable operating conditions. The environment may also be variable, regardless of the operating regime. Stiffeners or stringers are mainly provided to improve the strength and stability of the structures and to provide a means of slowing down or arresting the growth of

*For correspondence 
cracks in the panel. Most of the above structures are generally subjected to fatigue loading. The fatigue loading may be either constant amplitude loading (CAL) or variable amplitude loading (VAL). Remaining life or residual strength assessment of the cracked structural components in these structures will be helpful for their in-service inspection, planning, repair, retrofitting, rehabilitation, requalification and health monitoring. Further, it is essential to use the damage tolerant design concepts for designing some of the above structural components. A structural component is damage tolerant if it can sustain cracks of critical length safely until it is repaired or its economic service life has expired. Damage tolerant analysis provides information about the effect of cracks on the strength of the component/structure. This information is usually presented in the form of two diagrams, namely, the residual strength diagram and the crack growth diagram. Fracture mechanics is a tool employed for investigation of the crack growth and fracture behaviour of structural components that are subjected to fatigue loading.

In general, it is difficult to quantify stress intensity factor (SIF) for most of the practical applications. For these applications, SIF is generally calculated based on the procedures and simplified equations presented in handbooks (Rooke \& Cartwright 1976, Murakami 1988). However, these procedures/equations are applicable only for simple and standard structural components. During the last four decades, a great deal of research has been dedicated to the development of numerical/analytical methods for computation of SIF for stiffened and unstiffened plate panels subjected to uniaxial tensile stresses. Toor (1973) conducted an extensive review on damage tolerant design approaches for aircraft structures. It was pointed out that the residual strength analysis methodology, various crack propagation laws and fracture mechanics can be applied to evaluate damage tolerance capacity of built-up structural components under spectrum loading conditions. The results of the test and finite element analysis (FEA) of complex structures indicated that simple methods of fracture mechanics can be applied to find the degree of damage tolerance. Wood \& Howard (1975) discussed the significant factors leading to the development of damage tolerance criteria and illustrated the role of fracture mechanics in the analysis and testing aspects necessary to satisfy these requirements. Swift (1984) conducted fracture analysis of cracked stiffened structure based on displacement compatibility method. Residual strength was computed for a two bay skin crack with a broken stiffener condition. Brussat et al (1986) presented the details of damage tolerance assessment of aircraft attachment lugs. Toor \& Dagger $(1986,1987)$ explained the details of damage tolerant design of fuselage structures with longitudinal cracks and circumferential cracks. Cali \& Citarella (2004) presented a numerical procedure for residual strength assessment of a cracked butt-joint, based on R-curve analysis and plastic collapse prediction. LEFM principles were employed for assessment of residual strength. Wang et al (2006) presented a numerical method to predict the residual strength of a composite fuselage panel with discrete source damage. Crack growth resistance curve (R-curve) method was used to predict the residual strength. Nathan et al (2006) predicted residual strength of structural composites subjected to variable amplitude fatigue loading and environmental exposure. Experiments were also carried out on E-glass fibres and vinyl ester resin. Nathan et al (2008) proposed a simple model for residual strength prediction of composite material under constant amplitude loading and block spectrum loading. Zhong et al (2008) conducted experimental and analytical investigations on the residual strength of the stiffened LY12CZ aluminum alloy panels with widespread fatigue damage (WFD). The SIF at the tips of the lead crack and the adjacent WFD cracks of the stiffened aluminum alloy panels were calculated by compounding approach and finite element method (FEM), respectively. The residual strength of the stiffened panels with WFD was evaluated by the engineering method with plastic zone linkup criterion and FEM with apparent fracture toughness criterion respectively. The predicted residual strength agreed well with the experimental results. Uz et al 
(2009) studied the damage tolerance of an aerospace grade aluminum alloy (Al2139-T8) using a new design philosophy in skin and stringer geometries. Fatigue crack propagation (FCP) tests (on panels with crenellations) with crack growing perpendicular to the welded stringers were conducted under constant amplitude and spectrum loading conditions and the results were compared with the classical solution.

From the literature review, it has been observed that the research carried out on remaining life prediction and residual strength evaluation of stiffened panels by using fracture mechanics approach is very limited. In general, residual strength is evaluated using plastic collapse condition (net section collapse condition) or fracture toughness criterion. In the present investigation, another method based on remaining life approach is proposed to evaluate the residual strength. Further, it has also been observed that there is a need to evolve efficient methodologies for computation of SIF in the case of stiffened panels and to provide an integrated approach that would include fatigue crack growth models for remaining life and residual strength prediction.

To meet one of the requirements of the damage tolerant evaluation, this paper presents methodologies for remaining life and residual strength of stiffened panels under fatigue loading. SIF has been computed by using parametric equations developed by using numerically integrated modified virtual crack closure integral (NI-MVCCI) technique (Palani 2004, Palani et al 2005). Various methodologies for residual strength evaluation, namely, plastic collapse condition, fracture toughness criterion and remaining life approach have been described. From the studies, it has been observed that the predicted life is significantly higher with concentric and eccentric stiffener cases compared to the respective unstiffened cases. The predicted residual strength using remaining life approach will govern the design.

\section{Computation of SIF}

Prediction of the remaining life or residual strength of a fatigue-damaged structural component depends on proper understanding of the crack growth behaviour, which in turn relies on the computation of SIF accurately. SIF of structures/structural components can be computed by using LEFM principles. Irwin (1957) used the classical theory of elasticity to show that the stresses in the vicinity of the crack tip are of the form (figure 1)

$$
\sigma_{\mathrm{ij}} \propto \frac{1}{\sqrt{2 \pi \mathrm{r}}} \mathrm{f}_{\mathrm{ij}}(\theta)+\cdots,
$$

where $\mathrm{r}$ and $\theta$ form a polar co-ordinate system with their origin at the crack tip, as shown in figure 1 , and $\mathrm{f}_{\mathrm{ij}}$ is a function of $\theta$. The above equation can be written as

$$
\sigma_{\mathrm{ij}}=\frac{\mathrm{K}}{\sqrt{2 \pi \mathrm{r}}} \mathrm{f}_{\mathrm{ij}}(\theta)+\cdots,
$$

where

$$
\mathrm{K}=\beta \sigma \sqrt{\pi \mathrm{a}}
$$

where $\beta$ is a geometric correction factor and $\sigma$ is the stress to which the crack plane is subjected. The determination of SIF in complex geometries such as cracked stiffened plates is extremely difficult owing to the complexities introduced by the structural geometry and the nature of stress field at the crack tip. 


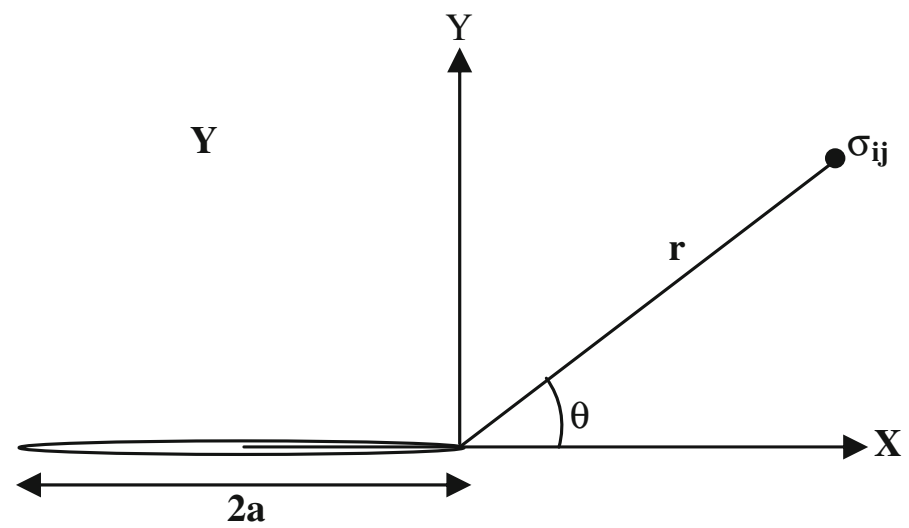

Figure 1. Crack tip co-ordinate system.

\subsection{SIF computation for stiffened panels}

Extensive work on fracture analysis of structural components was carried out by using the FEM (Palani 2004). It was observed from the studies conducted on the fracture analysis of plates that the performance of 9-noded Lagrangian element with assumed shear strain fields is better compared to the other quadrilateral plate elements considered (Palani 2004). This element was appropriately combined with 3-noded beam element for formulating MQL9S2 stiffened plate finite element (FE) model (Palani et al 2005). For tensile mode I and bending mode 1 fracture of stiffened panels, $\mathrm{G}_{I}$ and $\mathrm{G}_{1}$ can be evaluated by multiplying the stress/ moment distribution ahead of crack tip with the corresponding displacement/rotation distribution behind crack tip and integrating this product over $\Delta a$ (virtual increment of crack length). It may be noted that tensile mode I and bending mode 1 fracture are coupled for plates with eccentric stiffeners (refer figure 2) $\left(\mathrm{G}_{I}\right.$ and $\mathrm{G}_{1}$ are strain energy release rates corresponding to tensile and bending mode, respectively), in view of the transformation matrices related to MQL9S2 FE model. The stress/moment distribution on the crack extension and the crack opening displacement/rotation distribution should be evaluated after duly accounting for the stiffener elements in the respective plate finite elements. Let these be represented as $\sigma_{\text {yyp }}, \sigma_{\text {xyp }}, M_{\text {yyp }}, M_{\text {xyp }}$ and $Q_{\mathrm{zp}}$ and $U_{\mathrm{xp}}, U_{\mathrm{yp}}, U_{\mathrm{zp}}, \theta_{\mathrm{xp}}$ and $\theta_{\mathrm{yp}}$. The subscript 'p' indicates that stress/moment and displacement components are for that of a stiffened plate panel evaluated at the plate mid-surface level. The

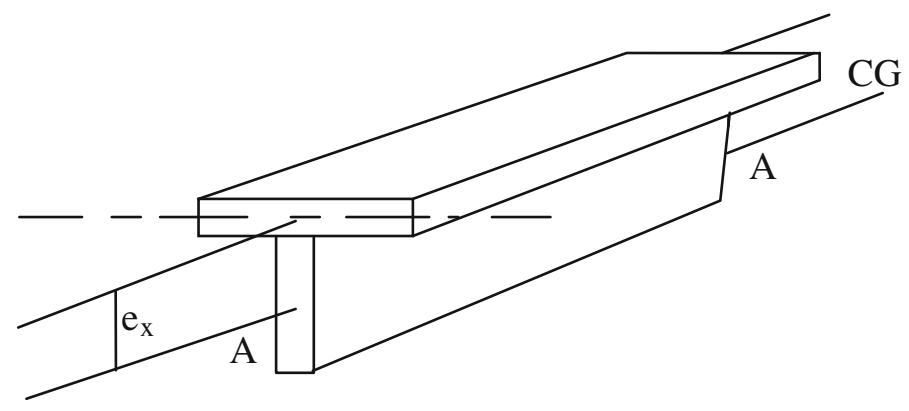

Figure 2. Plate with an eccentric stiffener. 
components of strain energy release rate can then be evaluated based on Irwin's theory using the force and displacement components, which can be expressed as

$$
\begin{aligned}
\mathrm{G}_{\mathrm{I}} & =\underset{\Delta a \rightarrow 0}{\mathrm{Lt}} \frac{1}{2 \Delta a} \int_{\Delta a} \sigma_{\mathrm{yyp}}(\xi) U_{\mathrm{yp}}\left(\xi^{\prime}\right) \mathrm{d} x, \\
\mathrm{G}_{1} & =\underset{\Delta a \rightarrow 0}{\mathrm{Lt}} \frac{1}{2 \Delta a} \int_{\Delta a} \mathrm{M}_{\mathrm{yyp}}(\xi) \theta_{\mathrm{yp}}\left(\xi^{\prime}\right) \mathrm{d} x, \\
\mathrm{G}_{\mathrm{II}} & =\underset{\Delta a \rightarrow 0}{\mathrm{Lt}} \frac{1}{2 \Delta a} \int_{\Delta a} \sigma_{\mathrm{xyp}}(\xi) U_{\mathrm{xp}}\left(\xi^{\prime}\right) \mathrm{d} x, \\
\mathrm{G}_{2} & =\underset{\Delta a \rightarrow 0}{\mathrm{Lt}} \frac{1}{2 \Delta a} \int_{\Delta a} Q_{\mathrm{zp}}(\xi) w_{\mathrm{p}}\left(\xi^{\prime}\right) \mathrm{d} x, \\
\mathrm{G}_{3} & =\underset{\Delta a \rightarrow 0}{\mathrm{Lt}} \frac{1}{2 \Delta a} \int_{\Delta a} \mathrm{M}_{\mathrm{xyp}}(\xi) \theta_{\mathrm{xp}}\left(\xi^{\prime}\right) \mathrm{d} x .
\end{aligned}
$$

The integrals given in Eq. (4) can be evaluated by using numerical integration technique. The integrals associated with the evaluation of the constants related to the stress/moment distribution and the above integrals are obtained by using Gauss numerical integration technique with an order of 3 applicable for 9-noded element with assumed transverse shear strain fields (Irwin 1957). Figure 2 shows a plate with an eccentric stiffener. If $e_{x}=0.0$, the plate will become case with concentric stiffener. Fracture analysis of cracked stiffened plates under combined tensile, bending and shear loads was conducted by employing MQL9S2 FE model (Irwin 1957). Equations $4 \mathrm{a}$ to $4 \mathrm{e}$ were the basic equations that are employed in the parametric studies to calculate the strain energy release rate corresponding to the respective fracture mode $\mathrm{K}_{\mathrm{I}}$ or $\mathrm{K}_{\mathrm{II}}$. Parametric studies on fracture analysis of stiffened plates subjected to tension-moment loads were conducted by employing NI-MVCCI technique and MQL9S2 FE model. Based on the parametric studies, the following equations were proposed for computation of SIF values of typical stiffened plates subjected to tensile-moment loads (Irwin 1957).

Case a: Tensile loading-Concentric stiffeners

For $x_{\mathrm{s}}=2$,

$$
\beta_{\mathrm{I}}=-73.501 \alpha_{\mathrm{a}}^{5}+118.377 \alpha_{\mathrm{a}}^{4}-73.068 \alpha_{\mathrm{a}}^{3}+22.436 \alpha_{\mathrm{a}}^{2}-4.125 \alpha_{\mathrm{a}}+0.581
$$

For $x_{\mathrm{s}}=25$,

$$
\beta_{\mathrm{I}}=-1.586 \alpha_{\mathrm{a}}^{3}+2.510 \alpha_{\mathrm{a}}^{2}-1.827 \alpha_{\mathrm{a}}+0.631
$$

For $x_{\mathrm{s}}=50$,

$$
\beta_{\mathrm{I}}=-0.8629 \alpha_{\mathrm{a}}^{3}+1.6822 \alpha_{\mathrm{a}}^{2}-1.5563 \alpha_{\mathrm{a}}+0.6332
$$

For $x_{\mathrm{s}}=100$,

$$
\beta_{\mathrm{I}}=-0.4843 \alpha_{\mathrm{a}}^{3}+0.9982 \alpha_{\mathrm{a}}^{2}-1.0924 \alpha_{\mathrm{a}}+0.6348
$$

For $x_{\mathrm{s}}=150$,

$$
\beta_{\mathrm{I}}=-0.3307 \alpha_{\mathrm{a}}^{3}+0.6351 \alpha_{\mathrm{a}}^{2}-0.6521 \alpha_{\mathrm{a}}+0.6349
$$

For $x_{\mathrm{s}}=200$,

$$
\beta_{\mathrm{I}}=-0.1283 \alpha_{\mathrm{a}}^{3}+0.2714 \alpha_{\mathrm{a}}^{2}-0.3234 \alpha_{\mathrm{a}}+0.6352
$$


Case b: Tensile loading-Eccentric stiffeners

For $x_{\mathrm{s}}=25$,

$$
\beta_{1}=89.65 \alpha_{i}^{7}-303.8 \alpha_{i}^{6}+412.8 \alpha_{i}^{5}-287.67 \alpha_{i}^{4}+109.04 \alpha_{i}^{3}-21.95 \alpha_{i}^{2}+2.03 \alpha_{i}+0.633
$$

For $x_{\mathrm{s}}=50$

$$
\beta_{1}=82.65 \alpha_{\mathrm{i}}^{7}-280.4 \alpha_{\mathrm{i}}^{6}+382.12 \alpha_{\mathrm{i}}^{5}-267.48 \alpha_{\mathrm{i}}^{4}+101.93 \alpha_{\mathrm{i}}^{3}-20.61 \alpha_{\mathrm{i}}^{2}+1.92 \alpha_{\mathrm{i}}+0.621
$$

For $x_{\mathrm{s}}=100$

$$
\beta_{1}=61.75 \alpha_{\mathrm{i}}^{7}-208.87 \alpha_{\mathrm{i}}^{6}+284 \alpha_{\mathrm{i}}^{5}-198.5 \alpha_{\mathrm{i}}^{4}+75.58 \alpha_{\mathrm{i}}^{3}-15.29 \alpha_{\mathrm{i}}^{2}+1.43 \alpha_{\mathrm{i}}+0.63
$$

For $x_{\mathrm{s}}=150$

$$
\beta_{1}=36.899 \alpha_{\mathrm{i}}^{7}-125.68 \alpha_{\mathrm{i}}^{6}+171.99 \alpha_{\mathrm{i}}^{5}-120.87 \alpha_{\mathrm{i}}^{4}+46.22 \alpha_{\mathrm{i}}^{3}-9.37 \alpha_{\mathrm{i}}^{2}+0.88 \alpha_{\mathrm{i}}+0.63
$$

For $x_{\mathrm{s}}=200$

$$
\beta_{1}=19.02 \alpha_{\mathrm{i}}^{7}-64.69 \alpha_{\mathrm{i}}^{6}+88.471 \alpha_{\mathrm{i}}^{5}-62.17 \alpha_{\mathrm{i}}^{4}+23.78 \alpha_{\mathrm{i}}^{3}-4.83 \alpha_{\mathrm{i}}^{2}+0.454 \alpha_{\mathrm{i}}+0.634(6 \mathrm{e})
$$

Case c: Moment loading-Concentric stiffeners

For $x_{\mathrm{s}}=2$,

$$
\beta_{1}=1.4699 \alpha_{\mathrm{a}}^{4}-3.1712 \alpha_{\mathrm{a}}^{3}+2.5486 \alpha_{\mathrm{a}}^{2}-1.0647 \alpha_{\mathrm{a}}+0.25587
$$

For $x_{\mathrm{s}}=25$,

$$
\beta_{1}=-0.4335 \alpha_{\mathrm{a}}^{3}+0.9064 \alpha_{\mathrm{a}}^{2}-0.8143 \alpha_{\mathrm{a}}+0.3178
$$

For $x_{\mathrm{s}}=50$,

$$
\beta_{1}=-0.3566 \alpha_{\mathrm{a}}^{3}+0.7739 \alpha_{\mathrm{a}}^{2}-0.7672 \alpha_{\mathrm{a}}+0.3231
$$

For $x_{\mathrm{s}}=100$,

$$
\beta_{1}=-0.3 \alpha_{\mathrm{a}}^{3}+0.6667 \alpha_{\mathrm{a}}^{2}-0.7285 \alpha_{\mathrm{a}}+0.3247
$$

For $x_{\mathrm{s}}=150$,

$$
\beta_{1}=-0.2297 \alpha_{\mathrm{a}}^{3}+0.5666 \alpha_{\mathrm{a}}^{2}-0.6819 \alpha_{\mathrm{a}}+0.3245
$$

For $x_{\mathrm{s}}=200$,

$$
\beta_{1}=-0.1233 \alpha_{\mathrm{a}}^{3}+0.4130 \alpha_{\mathrm{a}}^{2}-0.5895 \alpha_{\mathrm{a}}+0.3230
$$

Case d: Moment loading-Eccentric stiffeners

For $x_{\mathrm{s}}=5$,

$$
\beta_{1}=-24.9994 \alpha_{\mathrm{i}}^{5}+73.06 \alpha_{\mathrm{i}}^{4}-80.99 \alpha_{\mathrm{i}}^{3}+42.515 \alpha_{\mathrm{i}}^{2}-11.3838 \alpha_{\mathrm{i}}+1.806
$$

For $x_{\mathrm{s}}=25$,

$$
\beta_{1}=-19.2985 \alpha_{\mathrm{i}}^{5}+62.7769 \alpha_{\mathrm{i}}^{4}-76.182 \alpha_{\mathrm{i}}^{3}+43.109 \alpha_{\mathrm{i}}^{2}-12.263 \alpha_{\mathrm{i}}+1.9974
$$


For $x_{\mathrm{s}}=50$,

$$
\beta_{1}=-8.3121 \alpha_{\mathrm{i}}^{5}+39.3335 \alpha_{\mathrm{i}}^{4}-59.1464 \alpha_{\mathrm{i}}^{3}+38.3899 \alpha_{\mathrm{i}}^{2}-11.977 \alpha_{\mathrm{i}}+2.0276
$$

For $x_{\mathrm{s}}=100$,

$$
\beta_{1}=22.3863 \alpha_{\mathrm{i}}^{4}-47.701 \alpha_{\mathrm{i}}^{3}+35.6974 \alpha_{\mathrm{i}}^{2}-12.0033 \alpha_{\mathrm{i}}+2.0484
$$

For $x_{\mathrm{s}}=150$,

$$
\beta_{1}=-11.1204 \alpha_{\mathrm{i}}^{5}+45.1797 \alpha_{\mathrm{i}}^{4}-63.1028 \alpha_{\mathrm{i}}^{3}+39.373 \alpha_{\mathrm{i}}^{2}-12.1543 \alpha_{\mathrm{i}}+2.0856
$$

For $x_{\mathrm{s}}=200$,

$$
\beta_{1}=-29.5998 \alpha_{\mathrm{i}}^{5}+83.1355 \alpha_{\mathrm{i}}^{4}-88.594 \alpha_{\mathrm{i}}^{3}+45.0239 \alpha_{\mathrm{i}}^{2}-11.9976 \alpha_{\mathrm{i}}+2.1393
$$

where $\alpha_{\mathrm{a}}=\frac{\mathrm{A}_{\mathrm{s}}}{\mathrm{A}_{\mathrm{p}}+\mathrm{A}_{\mathrm{s}}}$ and $\alpha_{\mathrm{i}}=\frac{\mathrm{I}_{\mathrm{s}}}{\mathrm{I}_{\mathrm{p}}+\mathrm{I}_{\mathrm{s}}}, x_{\mathrm{s}}=$ distance of stiffener from crack tip, where $A_{\mathrm{s}}=$ Area of stiffener, $A_{\mathrm{p}}=$ Area of plate, $l_{\mathrm{s}}=$ moment of inertia of stiffener and $l_{\mathrm{p}}=$ moment of inertia of plate.

\section{Remaining life prediction}

The proposed methodology uses LEFM concepts for remaining life prediction. In LEFM, an elastic stress field is defined at crack tip and is characterized in terms of SIF alone. The rate of crack growth, $\mathrm{d} a / \mathrm{d} N$, in terms of the crack tip SIF range, $\Delta K$ can be expressed as

$$
\frac{\mathrm{d} a}{\mathrm{~d} N}=C(\Delta K)^{m} .
$$

Paris, Walker, Forman, Erdogan and Ratwani, Klesnil and Lucas, Forman-Newman-de Koning contributed with different models representing crack growth behaviour.

The number of loading cycles required to extend the crack from an initial length $a_{0}$ to the final critical crack length $a_{f}$ is given by

$$
N=\int_{a_{0}}^{a_{\mathrm{f}}} \frac{\mathrm{d} a}{C(\Delta K)^{m}},
$$

where $C$ and $m$ are crack growth constants and $\Delta K=$ range of SIF corresponding to the cyclic load $\Delta \sigma$.

\section{Residual strength evaluation of structural components}

Damage tolerance analysis provides capability for the calculation of both residual strength diagram (fracture due to cracks) and crack growth curve. Procedure for prediction of remaining life is described above. Residual strength can be computed by using (i) plastic collapse condition or yield criterion. (ii) Fracture toughness criterion. (iii) Remaining life approach. 
The residual strength of a plate/panel is the least value obtained by using the above three criterions. In general, construction of a residual strength diagram involves three major steps:

(a) Development of the relationship between the applied stress $\sigma$, the crack length parameter ' $a$ ' and the ' $K$ ' for the given structural configuration.

(b) Selection of an appropriate failure criterion based on the expected material behaviour at the crack tip.

(c) Computation of fracture strength $\left(\sigma_{\mathrm{fc}}\right)$ values for critical crack sizes $\left(a_{\mathrm{c}}\right)$ by utilizing the results of the first two steps (a and b). The residual strength diagram ( $\left.\sigma_{\mathrm{fc}} \mathrm{vs} a_{\mathrm{c}}\right)$ for the given structural configuration is plotted where $a=$ half-length of the crack, $\beta=$ geometry factor.

Hence, such a plate with a half crack $a_{\mathrm{x}}$ will fracture when the applied stress $\sigma_{\mathrm{x}}$ satisfies based on these values.

\subsection{Plastic collapse condition}

In the plane stress condition, where the stress in the entire cross section is equal to yield strength at the time of collapse, the maximum load carrying $\left(P_{\max }\right)$ capacity of the plate with an edge crack is (David Broek 1989)

$$
P_{\max }=t(W-a) \sigma_{\mathrm{y}},
$$

where $a=$ crack length, $W=$ total width, $t=4$ thickness, and $\sigma_{\mathrm{y}}=$ yield strength.

This failure load is called the collapse load or the limit load.

The nominal stress in full width of the component is,

$$
\sigma=\frac{P_{\max }}{\mathrm{Wt}} .
$$

Hence, the component fails when the nominal stress is

$$
\sigma_{\mathrm{fc}}=\frac{P_{\mathrm{max}}}{W t}=\frac{t(W-a) \sigma_{\mathrm{y}}}{W t} .
$$

If $a=W$, failure will occur when the nominal stress $\sigma_{\mathrm{fc}}=0$.

\subsection{Fracture toughness criterion}

The nominal stress at which fracture takes place, will be denoted as $\sigma_{\mathrm{fc}}$

$$
\sigma_{\mathrm{fc}}=\frac{\text { Fracture toughness }}{\beta \sqrt{\pi a}},
$$

where $\sigma_{\mathrm{fc}}$ is the residual strength or the remaining strength under the presence of cracks.

\subsection{Remaining life approach}

Irwin proposed the following SIF $K_{\mathrm{S}}$ to quantify the intensity of the stress field surrounding the crack tip in a finite width plate with a remote stress, $\sigma$ :

$$
\begin{gathered}
K_{\mathrm{s}}=\beta \sigma \sqrt{\pi a} \\
K_{\mathrm{c}}=\beta \sigma_{\mathrm{x}} \sqrt{\pi a_{\mathrm{x}}},
\end{gathered}
$$


where $K_{\mathrm{c}}=$ critical SIF, which is a material parameter. The rate at which the crack grows under constant amplitude cyclic loading can be derived using Eq. (9) that was proposed by Paris \& Erdogan (1963).

This equation can be expressed in integral form to give the number of cycles $N_{\mathrm{f}}$ as given by Eq. (10) that are required for a crack of initial length $2 a_{\mathrm{i}}$ to propagate to a crack length $2 a_{\mathrm{x}}$ :

From Eq. (15)

$$
\Delta K=\beta \Delta \sigma \sqrt{\pi a}
$$

and from eqn. (16)

$$
a_{\mathrm{x}}=\frac{K_{\mathrm{c}}^{2}}{\beta^{2} \sigma_{\mathrm{x}}^{2} \pi} .
$$

Substituting Eqs.(17) and (18) into Eq. (9) and integrating gives the following residual strength curve, where $\sigma_{\mathrm{c}}$ is the residual strength after $N_{\mathrm{c}}$ cycles of load:

$$
N_{\mathrm{c}}=D_{1}-S_{1}\left(1 / \sigma_{\mathrm{c}}^{2}\right)^{(1-(m / 2))},
$$

where

$$
D_{1}=\frac{\left(2 a_{i}\right)^{1-(m / 2)}}{\left[C \beta^{m}(\Delta \sigma)^{m} \pi^{\frac{m}{2}}\left(\frac{m}{2}-1\right)\right]}
$$

and

$$
S_{1}=\frac{\left(\frac{2 K_{c}^{2}}{\beta^{2} \pi}\right)^{1-(m / 2)}}{\left[C \beta^{m}(\Delta \sigma)^{m} \pi^{\frac{m}{2}}\left(\frac{m}{2}-1\right)\right]},
$$

where for a fixed initial crack size $a_{\mathrm{i}}$, the parameters $D_{1}$ and $S_{1}$ are constants.

\section{Numerical studies}

To demonstrate the methodologies described above, studies have been conducted for remaining life prediction and residual strength assessment. Two example problems, namely, (i) plate with a centre crack made up of 350 WT steel and (iii) stiffened plate with centre crack made up of 2024-T3 Al alloy subjected to constant amplitude loading have been presented below.

\subsection{Plate with centre crack-350 WT Steel}

This problem was studied by Taheri et al (2003). The data/information related to this problem is given below (table 1).

Remaining life has been predicted for the above problem and it can be observed that the predicted life is in good agreement with the corresponding experimental value available in the literature (Taheri et al 2003).

Present study

Experimental (Taheri et al 2003)

$\%$ difference
138750 cycles

156000 cycles

11.05 .

Figure 3 shows the plot of crack length vs residual strength predicted by using plastic collapse condition (yield condition), fracture toughness criterion and remaining life approach. It can be observed from figure 3 that the residual strength values predicted by using other two approaches. 
Table 1. Plate with centre crack $350 \mathrm{WT}$ steel.

\begin{tabular}{lc}
\hline Material dimensions & $350 \mathrm{WT}$ steel $100 \times 300 \times 5 \mathrm{~mm}$ \\
\hline Fracture toughness & $50 \mathrm{MPa} \sqrt{m}$ \\
Yield strength & $350 \mathrm{MPa}$ \\
Stress ratio & 0.1 \\
Stress condition & Plane stress \\
Maximum stress & $114 \mathrm{MPa}$ \\
Minimum stress & $11.4 \mathrm{MPa}$ \\
Crack growth Eqn. & Paris \\
$C$ & $1.02 \mathrm{e}-08$ \\
$m$ & 2.94 \\
Initial crack length $\left(a_{\mathrm{i}}\right)$ & $10 \mathrm{~mm}$ \\
\hline
\end{tabular}

\subsection{Stiffened plate with centre crack 2024-T3 Al alloy}

Another example problem, stiffened plate with a centre crack has been studied for remaining life and residual strength evaluation (figure 4). This problem was studied by Dawicke (1997). The data/information related to this problem is given below (table 2). Concentric and eccentric stiffening cases have been considered for remaining life and residual strength evaluation.

Remaining life has been predicted without stiffener and observed that it is in good agreement with the corresponding value available in the literature.

Present study

$$
\begin{array}{ll}
\text { Present study } & =28733 \text { cycles } \\
\text { Experimental (Dawicke 1997) } & =30719 \text { cycles } \\
\% \text { difference } & =6.91 .
\end{array}
$$$$
\% \text { difference }
$$

5.2a Concentric stiffener case: In the case of concentric stiffener, remaining life and residual strength have been predicted for the stiffener located at $X_{\mathrm{s}}=6.35 \mathrm{~mm}$ and at the edges. Table 1 shows the predicted remaining life for different stiffener sizes and positions under CAL. Table 1 also shows the comparison of predicted remaining life for different stiffener sizes with the corresponding values of unstiffened case. It was also found that there is about $20 \%$ decrease in SIF as the crack grows from initial to final length in the case of plate with stiffener compared

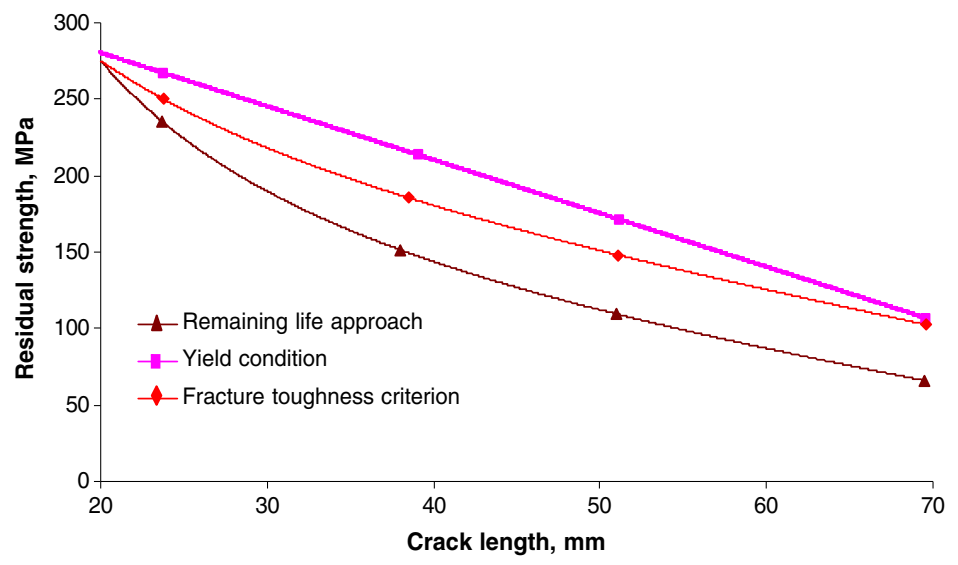

Figure 3. Crack length vs. residual strength. 


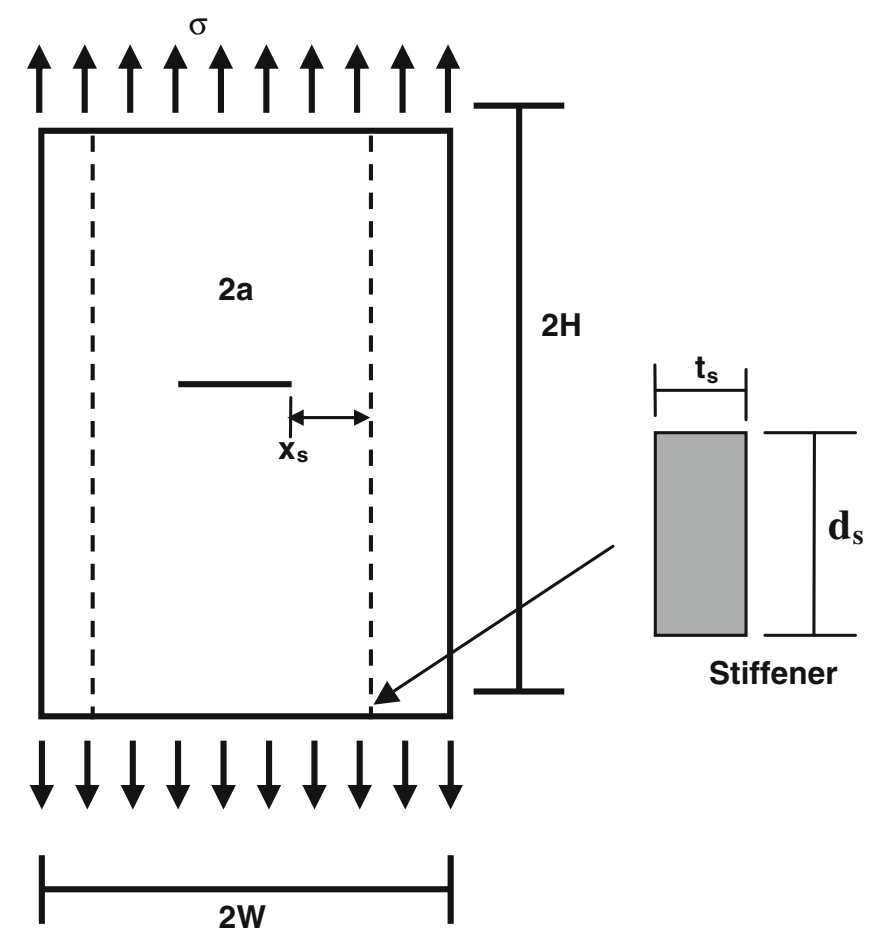

Figure 4. Stiffened plate with centre crack.

to unstiffened case. Figure 5 shows the variation of predicted remaining life under CAL for different stiffener sizes including the unstiffened case. From table 1 and figure 5, it can be observed that the predicted life of stiffened panel under CAL increases with increase of stiffener area and is about $1267 \%$ higher for stiffener area of $36 \mathrm{~mm}^{2}$ compared to the respective unstiffened case. It can also be observed that the predicted life is significantly higher for the stiffener located at $X_{\mathrm{s}}=6.35 \mathrm{~mm}$ compared to the case of stiffener located at the edges. Figure 6a shows the predicted residual strength using remaining life approach for the stiffener

Table 2. Plate with centre crack 2024-T3 Al alloy.

\begin{tabular}{lc}
\hline Material & 2024-T3 Al alloy \\
\hline Plate dimensions & $76.2 \times 127 \mathrm{~mm}$ \\
Thickness & $2.286 \mathrm{~mm}$ \\
Fracture toughness & $50.54 \mathrm{MPa} \sqrt{m}$ \\
Yield strength & $665.38 \mathrm{MPa}$ \\
Stress ratio & 0.02 \\
Stress condition at crack tip & Plane stress \\
Maximum stress $\left(\sigma_{\max }\right)$ & $68.94 \mathrm{MPa}$ \\
Crack growth equation & Paris \\
$C$ & $0.829 \mathrm{e}-8$ \\
$m$ & 2.284 \\
Initial crack length & $25.4 \mathrm{~mm}$ \\
Maximum stress $\left(\sigma_{\max }\right)$ & $68.94 \mathrm{MPa}$ \\
\hline
\end{tabular}




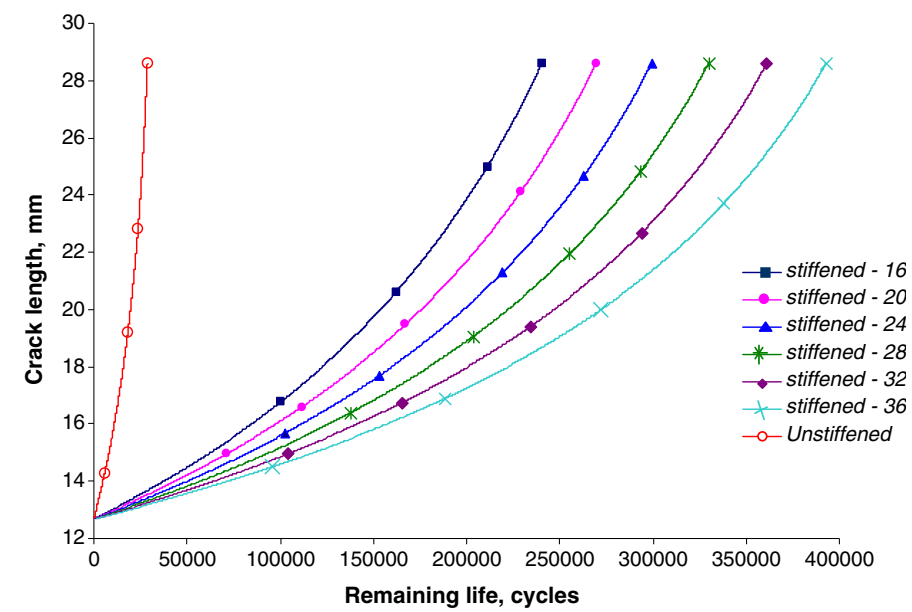

Figure 5. Remaining life for different stiffener sizes.
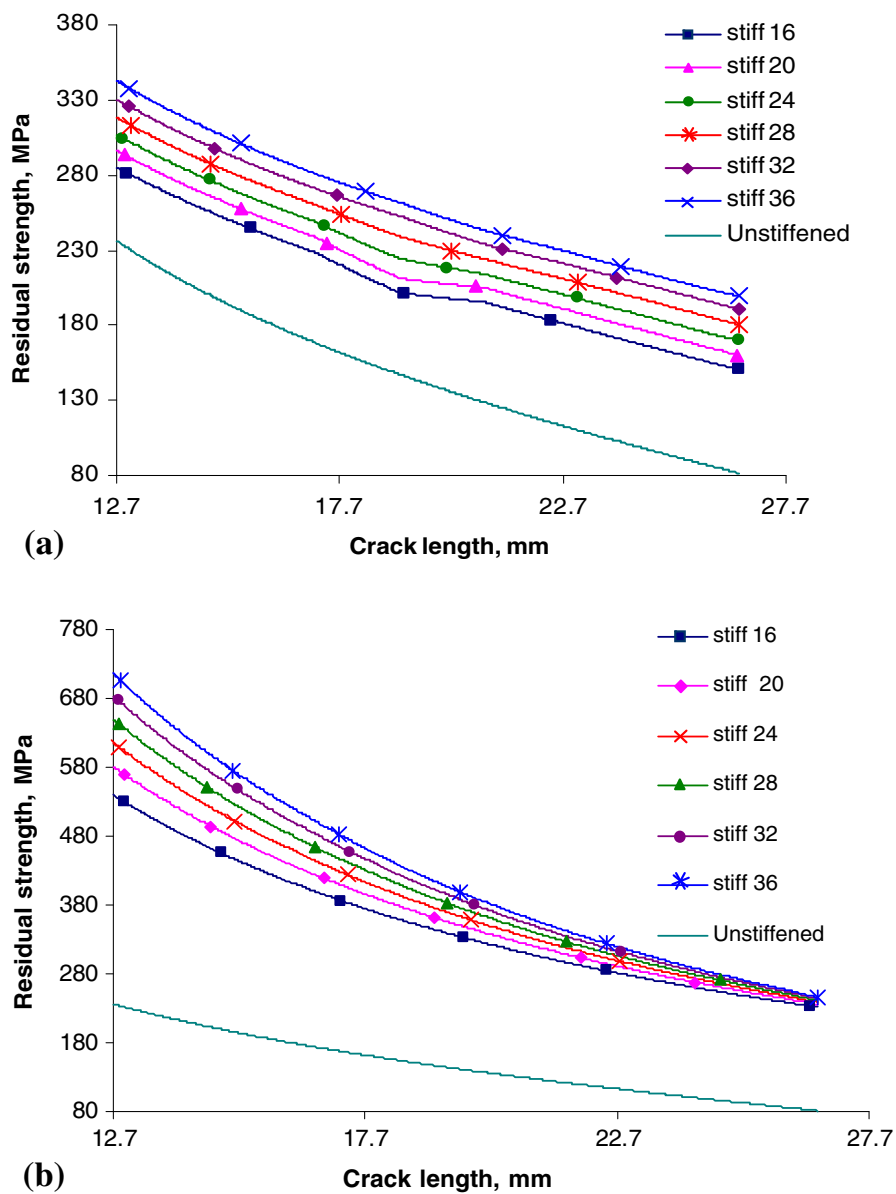

Figure 6. Half crack length vs. residual strength (a) Stiffener at edges (b) Stiffener at $6.35 \mathrm{~mm}$. 
areas of 16, 20, 24, 28, 32 and $36 \mathrm{~mm}^{2}$ and unstiffened case. Stiffener is positioned at edges. From figure $6 \mathrm{a}$, it can be observed that, the predicted residual strength increases with increase of stiffener area. The predicted residual strength is $20.71 \%$ and $45.11 \%$ higher for the stiffener areas 16 and $36 \mathrm{~mm}^{2}$, respectively compared to unstiffened case. Figure $6 \mathrm{~b}$ shows the predicted residual strength using remaining life approach for the stiffener areas of 16, 20, 24, 28, 32 and $36 \mathrm{~mm}^{2}$ and unstiffened case. Stiffener is positioned at $6.35 \mathrm{~mm}$ from crack tip. From figure $6 \mathrm{~b}$, it can be observed that the predicted residual strength increases significantly with increase of stiffener area compared to unstiffened case. The predicted residual strength is $128.57 \%$ and $201.48 \%$ higher for the stiffener cases with area of 16 and $36 \mathrm{~mm}^{2}$, respectively compared to unstiffened case. From figure $6 \mathrm{~b}$, it can also be observed that the difference in the predicted residual strength for the stiffener case with area of 16 and $36 \mathrm{~mm}^{2}$ reduces gradually with increase in crack length. From figure $6 a$ and $b$, it can be observed that the percentage increase in the predicted residual strength when the stiffener is placed at $6.35 \mathrm{~mm}$ is $89.36 \%, 95.92 \%, 100.41 \%$, $104.04 \%, 106.81 \%$ and $108.94 \%$ for the stiffener areas of 16, 20, 24, 28, 32 and $36 \mathrm{~mm}^{2}$, respectively compared to that of the stiffener placed at the edges and for the same stiffener areas. Further, it can be observed from figure $6 a$ and $b$ that in the case of stiffener at edges the rate of decrease in residual strength with respect to crack length is uniform for all the stiffness sizes, whereas for the case of stiffener at $6.35 \mathrm{~mm}$, the rate of decrease is gradually varying for different stiffener sizes.

5.2b Eccentric stiffener case: In this case, remaining life has been predicted for the stiffener position at $X_{\mathrm{S}}=6.35 \mathrm{~mm}$. Table 2 shows the predicted remaining life for different stiffener moments of inertia (MIs). Figure 7 shows the variation of predicted remaining life for different stiffener MIs including the unstiffened case. In the case of eccentric stiffener, it has been observed that SIF reduces approximately by $10 \%$ compared to unstiffened case. From figure 7 , it can be observed that the predicted life of stiffened panel increases with increase of stiffener MI and is about $379 \%$ higher for stiffener MI of $333 \mathrm{~mm}^{4}$ compared to the respective unstiffened case. Figure 8 shows the predicted residual strength using remaining life approach for the stiffener MI of 0.5, 3, 10.66, 23.04, 74.09 and $149.38 \mathrm{~mm}^{4}$ and unstiffened case. For this case also, stiffener position is assumed to be $6.35 \mathrm{~mm}$. From figure 8, it can be observed that the predicted residual strength is larger for all the stiffener MIs compared to unstiffened case (62.9 to 69.12\%). Further, it can be observed that the predicted residual strength increases with the increase of

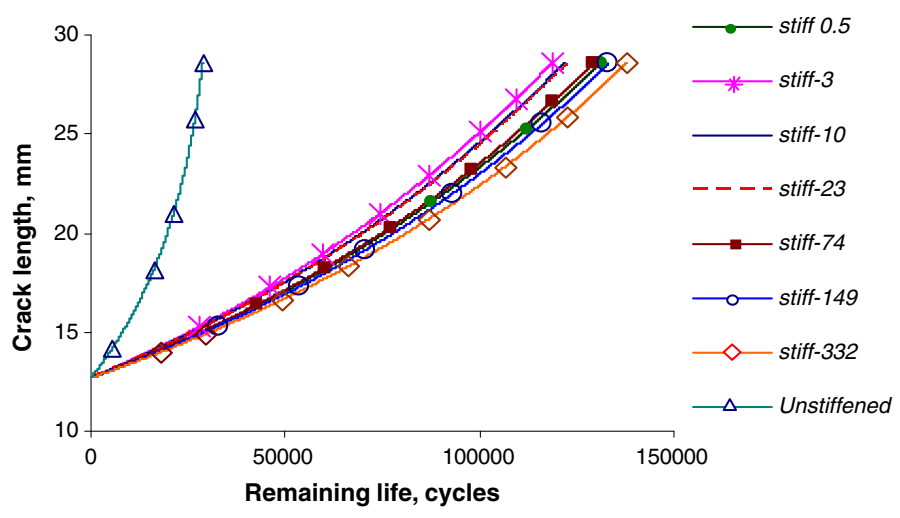

Figure 7. Remaining life for different stiffener MIs (Stiffener at $6.35 \mathrm{~mm}$ ). 


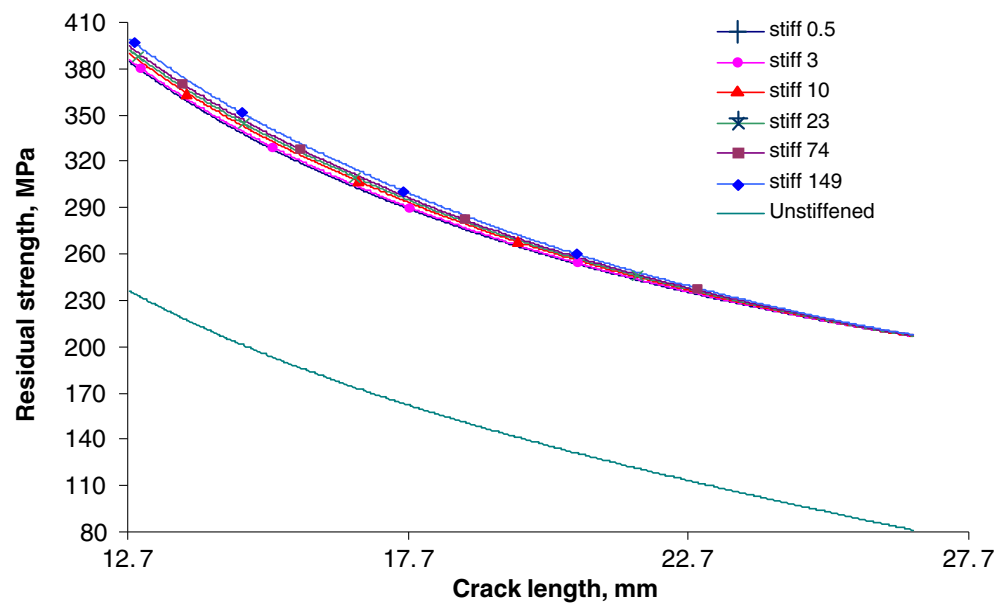

Figure 8. Residual strength for different stiffener MIs (eccentric case) (Stiffener at $6.35 \mathrm{~mm}$ ).

Table 3. Remaining life (in cycles) for a plate with concentric stiffener.

\begin{tabular}{lcccc}
\hline $\begin{array}{l}\text { Stiffener } \\
\text { area }\left(\mathrm{mm}^{2}\right)\end{array}$ & $\begin{array}{c}\text { Predicted remaining } \\
\text { life when stiffener } \\
\text { at } X_{\mathrm{s}}=6.35 \mathrm{~mm}\end{array}$ & $\begin{array}{c}\text { \% diff. compared to } \\
\text { unstiffened plate }\end{array}$ & $\begin{array}{c}\text { Predicted remaining } \\
\text { life when stiffener } \\
\text { at edges }\end{array}$ & $\begin{array}{c}\text { \% diff. compared to } \\
\text { unstiffened plate }\end{array}$ \\
\hline Unstiffened & 28733 & - & 28733 & - \\
16 & $2.4029 \times 10^{5}$ & 736.28 & 48434 & 68.56 \\
20 & $2.6928 \times 10^{5}$ & 837.18 & 54190 & 88.59 \\
24 & $2.9913 \times 10^{5}$ & 941.07 & 60565 & 110.79 \\
28 & $3.2976 \times 10^{5}$ & 1047.67 & 68087 & 136.96 \\
32 & $3.6104 \times 10^{5}$ & 1156.53 & 75954 & 164.34 \\
36 & $3.928 \times 10^{5}$ & 1267.07 & 83135 & 189.34 \\
\hline
\end{tabular}

Table 4. Remaining life (in cycles) for plate with a centre crack (eccentric stiffener).

\begin{tabular}{lcc}
\hline Stiffener MI $\left(\mathrm{mm}^{4}\right)$ & Remaining life & \% diff. compared to unstiffened plate \\
\hline Unstiffened & 28733 & - \\
0.5 & $1.3099 \times 10^{5}$ & 355.88 \\
2.99 & $1.1845 \times 10^{5}$ & 312.24 \\
10.66 & $1.217 \times 10^{5}$ & 323.55 \\
23.04 & $1.2257 \times 10^{5}$ & 326.58 \\
74.09 & $1.2903 \times 10^{5}$ & 349.06 \\
149.38 & $1.3309 \times 10^{5}$ & 363.19 \\
332.98 & $1.3773 \times 10^{5}$ & 379.34 \\
\hline
\end{tabular}

stiffener size. But the increase in the predicted residual strength is marginal with the increase of MI. As observed for the case of concentric stiffness, the rate of decrease of residual strength with respect to crack length is varying gradually for different stiffener sizes (tables 3 and 4). 


\section{Summary and Conclusion}

To meet one of the requirements of damage tolerant evaluation, fracture mechanics-based methodologies have been developed for remaining life prediction and residual strength evaluation of stiffened panels under fatigue loading. SIF computation has been carried out by using the parametric equations based on NI-MVCCI technique. Procedure for remaining life prediction is outlined. Various methods for residual strength evaluation, namely, plastic collapse condition, fracture toughness criterion and remaining life approach have been explained. Numerical studies have been conducted on plate with centre crack and a stiffened panel with centre crack subjected to tensile loading. Concentric and eccentric stiffener cases have been considered in the studies. From the studies, it has been observed that the predicted life is significantly higher with concentric and eccentric stiffener cases compared to the respective unstiffened cases. The percentage increase in life is relatively more in the case of concentric stiffener compared to that of eccentric stiffener case for the same stiffener size and moment of inertia. From the studies, it has also been observed that the predicted residual strength using remaining life approach is lesser compared to other methods, namely, plastic collapse condition and fracture toughness criterion and hence remaining life approach will govern the design. It is noted that residual strength increases with the increase of stiffener size. It is further observed that in the case of stiffener placed at edges the rate of decrease in residual strength with respect to crack length is uniform for all

stiffener sizes, whereas for the case of intermediate stiffener, the rate varies gradually for different stiffener sizes.

We thank for the valuable technical suggestions and support provided by our colleagues Mr J. Rajasankar, Deputy Director and Ms. Smitha Gopinath, Scientist of SERC for useful technical discussions during the course of this investigation. This paper is being published with the permission of the Director, SERC, Chennai, India.

\section{References}

Brussat T R, Kathiresan K and Rudd J L (1986) Damage tolerance assessment of aircraft attachment lugs, Eng. Fracture Mech. 23: 1067-1084

Cali C and Citarella R (2004) Residual strength assessment for a butt-joint in MSD condition, Adv. Eng. Software 35: 373-382

David Broek (1989) The practical use fracture mechanics (Netherlands: Kluwer Academic Publishers)

Dawicke D S C (1997) Overload and underload effects on the fatigue crack growth behaviour of the 2024T3 Aluminum Alloy, NASA Contractors Report 201668

Irwin G R (1957) Analysis of stress and strain near the end of a crack traversing a plate, J. Appl. Mech. 24 Murakami Y (1988) Stress intensity factors handbook (Oxford: Pergamon Press)

Nathan L, Post John Bausano Scott Case W and John Lesko J (2006) Modelling the remaining strength of structural composite materials subjected to fatigue, Int. J. Fatigue 28: 1100-1108

Nathan L, Post J, Cain K J, Mc Donald S W case and Lesko J J (2008) Residual strength prediction of composite materials: Random spectrum loading, Eng. Fracture Mech. 75: 2707-2724

Palani G S (2004) Numerically integrated MVCCI technique for fracture analysis of plates and stiffened panels, $\mathrm{PhD}$ thesis. Indian Institute of Science, Bangalore

Palani G S, Nagesh R Iyer and Dattaguru B (2005) Fracture analysis of cracked stiffened panels under combined tensile bending and shear loads, AIAA J. 43: 2039-2045

Paris P C and Erdogan F (1963) A critical analysis of crack propagation laws, J. Basic Eng. 85: 528-534

Rooke D P and Cartwright D J (1976) Compendium of stress intensity factors. Her Majesty's Stationary Office, London 
Swift T (1984) Fracture analysis of stiffened structure. Damage tolerance of metallic structures, Analysis Methods and Application. ASTM STP842, pp. 69-107

Taheri F, Trask D and Pegg N (2003) Experimental and analytical investigation of fatigue characteristics of 350WT steel under constant and variable amplitude loadings, Marine Struct. 16: 69-91

Toor M P (1973) A review of some damage tolerance design approaches for aircraft structures, Eng. Fracture Mech. 5: 837-876

Toor M P and Dagger D (1986) On damage tolerance design of fuselage structure (longitudinal cracks), Eng. Fracture Mech. 24: 915-927

Toor M P and Dagger D (1987) On damage tolerance design of fuselage structure (circumferential cracks), Eng. Fracture Mech. 26: 771-782

Uz M V, Koçak M, Lemaitre F J, Ehrstrom C, Kempa S and Bron F (2009) Improvement of damage tolerance of laser beam welded stiffened panels for airframes via local engineering, Int. J. Fatigue 31: 916-926

Wang J T, Clarence C, Poe Damodar R Ambur and David W Sleight (2006) Residual strength prediction of damaged composite fuselage panel with R-curve method, Composites Science and Technology 66: $2557-2565$

Wood A and Howard (1975) Application of fracture mechanics to aircraft structural safety, Eng. Fracture Mech. 7: 557-558

Zhong Li, Ge Sen, Lu Guozhi, Chen Li, and Ding Huiliang (2008) Residual strength of stiffened LY12CZ aluminum alloy panels with widespread fatigue damage, Chinese J. Aeronautics 21: 48-52 